\title{
Descriptive Epidemiology, Medical Evaluation, and Outcomes of Rock Climbing Injuries
}

\author{
James W. McDonald, MD; A. Michael Henrie, DO; Masaru Teramoto, PhD, MPH; Edward Medina, RN BSN; \\ Stuart E. Willick, MD \\ From Physical Medicine \& Rehabilitation, Sheridan VA Medical Center, Sheridan, Wyoming (Dr McDonald); Physical Medicine \& Rehabilitation, \\ University of Utah, Salt Lake City, Utah (Drs Henrie, Teramoto, and Willick); and the Emergency Department, Montrose Memorial Hospital, \\ Montrose, Colorado (Mr Medina).
}

\begin{abstract}
Objective.-To gather epidemiologic data on injury type, treatment, and recovery from rock climbing injuries.

Methods.-Design: retrospective cross-sectional study. Setting: web-based survey. Participants: rock climbers who sustained a climbing-related injury during the prior 24 months. Criteria for inclusion: aged $\geq 18$ years; participation in rock climbing at least 4 times per year in the United States. Interventions: none. Main outcome measures: percentage of injured climbers seeking medical care, providers seen, subspecialty referral, development of chronic problems, factors affecting return to climbing, injuries by climbing type, body region, and injury type.

Results.-Data were collected over a 60-day period using the Research Electronic Data Capture (REDCap) survey system. Seven hundred and eight surveys were collected from 553 male and 155 female climbers. Thirteen hundred ninety seven injuries were reported, and 975 injuries were suitable for analysis. The most common provider initially seen was a primary care provider. Subspecialty referral was commonly obtained. Injury patterns differed by climbing type. The percentage of respondents that returned to climbing before their injury was fully healed was $51.1 \%$, and $44.9 \%$ of respondents developed chronic problems related to their climbing injury. Twenty-eight percent of respondents were unable to return to their previous level of climbing performance. Several factors were associated with delayed recovery from climbing injury.

Conclusions.-A significant number of climbers sought healthcare after injury. A majority of climbers who sought treatment were referred to subspecialist providers. About one-half of climbers were symptomatic when they returned to climbing and developed chronic problems after injury. Factors associated with slower return to climbing included increasing age, smoking, fractures, and surgery.
\end{abstract}

Keywords: rock climbing, sports injuries, treatment, recovery, epidemiology

\section{Introduction}

Rock climbing continues to increase in popularity. Among outdoor sports, only water sports, adventure racing, and triathlons have seen more new participants in recent years. ${ }^{1}$ The growth in the number of indoor climbing facilities has greatly increased accessibility in areas of the country with limited outdoor climbing opportunities. Current sports participation data from 2012 indicate that there are over 6 million rock

Corresponding author: James W. McDonald, MD, Chief, Physical Medicine \& Rehabilitation, Sheridan VA Medical Center, Sheridan, Wyoming 82801; e-mail: james.mcdonald4@va.gov.

Submitted for publication November 2016.

Accepted for publication May 2017. climbing participants in the United States. ${ }^{1}$ This figure represents $2.4 \%$ of the general population over the age of 6 , with the highest participation rates among those aged 6 to $24 .^{1}$ There is high regional variability in climbing participation. Recent data from Utah, where indoor and outdoor climbing is readily accessible, indicate that $13.3 \%$ of adults participated in rock climbing at least once during the prior 12 months. ${ }^{2}$ As climbing grows in popularity, so does the need to better understand climbing-related injuries and treatment.

There are 4 general categories of technical rock climbing that were included in this study. The first is indoor or gym climbing. With this type of climbing, participants ascend on built walls using artificial holds on engineered routes using both lead climbing and top roping 
techniques. The "deck" or floor is generally well-padded, and the anchors in the wall are very stable and reliable. These engineered routes are graded by the Yosemite Decimal Rating System and range in difficulty from easy (grades 5.4-5.5) to exceptionally challenging (grades 5.14-5.15). ${ }^{3}$ Indoor routes tend to be more overhanging and may involve more dynamic movements. The second type of climbing is traditional or "trad" climbing, and occurs outdoors. With traditional climbing, a climber or a group of climbers will place all the safety gear required to protect from a fall. Safety gear, commonly referred to as "protection," or "pro" is placed in the rock wall as the climber advances up a cliff face, and is usually removed once passage of the group is complete. The third type of climbing is outdoor sport climbing. Participants rely on permanent anchors that have previously been bolted or otherwise fixed to the rock. Since there is not a need to "place protection," this form of climbing tends to focus more on strength and gymnastic ability, often requiring the performance of difficult maneuvers. The fourth form of climbing is bouldering. This is performed without safety gear, and is generally limited to very short climbs. A portable pad referred to as a "crash pad" is usually placed on the ground at the bottom of the climb to provide cushion in the event of a fall. This form of climbing generally occurs on large outdoor boulders, but can also occur on artificial indoor boulders and short climbing walls. Bouldering generally involves difficult maneuvers that require short bursts of significant strength, endurance, and flexibility.

Several prior epidemiologic studies have been performed attempting to evaluate both the body regions and types of injuries sustained by climbers. Experts believe that an injury risk for rock climbing is lower than that for playing football or horse riding. ${ }^{4}$ Yet, climbing-related injuries may be unusual, and physicians need to be aware of orthopedic injuries specifically sustained by climbers. Research has shown that strain and overuse injuries are the most frequent injuries sustained by climbers, and these are more likely to affect the upper extremities. ${ }^{5-7}$ Traumatic, fall-related injuries are less common, and are more likely to affect the lower extremities. ${ }^{5,7}$ In one of the larger epidemiologic studies, Gerdes et al reported on 2472 injuries among 1887 climbers. $^{6}$ This study found that upper limb injuries accounted for $57.6 \%$ of all injuries reported. Injuries involving the fingers represented $27.5 \%$ of the injuries in this study. Strain/ Sprain and chronic overuse injuries of the fingers were reported as the most common types of injuries. The percentage of reported injuries in this study that affected the lower limb was $27.6 \%$, with the ankle being the most common site of injury (12.6\%). Lacerations and fractures were more common in the lower limb than the upper limb. Backe et al conducted a similar mail-based survey that was sent out to 560 members of a Swedish climbing club. ${ }^{5}$ Three hundred fifty-five respondents reported 194 chronic injuries and 14 traumatic injuries. Hand, finger, and wrist injuries represented $42 \%$ of all overuse injuries. The number of traumatic injuries in this study was small, but also most frequently involved the lower limb. The injury incidence reported in this study was 4.2 injuries per 1000 climbing hours. Investigators in Germany have reported lower injury incidences. ${ }^{8,9}$ Another study also indicated an extremely low rate of climbing-related injuries, as it was reported that there were 55 significant injuries from more than 1 million visits to 56 climbing walls in England, Scotland, and Wales. ${ }^{10}$ Jones et al administered an in-person survey at both indoor and outdoor climbing locations in the United Kingdom. ${ }^{7}$ Fifty percent of those surveyed had sustained at least 1 injury during the 12 prior months. Overuse (33\%) and strain type injuries (28\%) were the most common, with only $10 \%$ of all injures being traumatic or fall-related in this study. Logan and colleagues found that a greater climbing intensity was associated with a higher risk of hand and wrist injuries. ${ }^{11}$ Addiss et al looked at climbingrelated injuries in the US National Parks over a 2-year period. $^{12}$ They reported that there were 127 injuries, with 36 of them (28\%) being fatal, and that $75 \%$ of all climbing-related injuries were due to falls.

Despite the growing data on the epidemiology of rock climbing-related injuries, little is known about the medical evaluation and treatment of these injuries. The article by Jones $^{7}$ reported that $38 \%$ of climbers sought medical evaluation for their injuries. Other studies have reported on climbing injuries presenting to the emergency department (ED) and other acute care settings. ${ }^{13,14}$ However, there is a paucity of research on the types of medical professionals seen by climbers, and the role of imaging studies. The nature of injuries sustained in different types of climbing has also not been well reported. Furthermore, the factors associated with delayed recovery from climbing injury and the development of chronic problems have not been previously established. The exception would be finger pulley and flexor tendon injuries, for which the mechanisms of injury, diagnosis, and treatment have been well described. ${ }^{15,16}$ The aims of this study were to expand upon existing data regarding the types of injuries sustained by type of climbing activity, to describe patterns of medical evaluations, and to identify factors associated with injury and recovery.

\section{Methods}

The survey study was approved by the University of Utah Institutional Review Board (IRB 00063354). 
The survey link was posted on a popular climbing website (www.mountainproject.com). Participants reviewed a consent document prior to completing the online survey. No personally identifying information was collected. Survey responses were collected using Research Electronic Data Capture (REDCap) survey software. Data was collected over a 60-day period from December 2013 to February 2014.

\section{Participants}

The survey was targeted at rock climbers who had sustained 1 or more climbing-related injuries in the 24 months prior to survey administration. Inclusion criteria for the study included: age $>18$ years, active participation in rock climbing at least 4 times per year, and climbing location primarily in the United States.

\section{Outcome Measures}

Participants were asked to indicate the body location affected, the type of injuries sustained, and the type of climbing activity in which the injury was sustained. Climbers were also asked if they sought medical care for their climbing-related injuries and what type of medical provider first evaluated them. Climbers were queried regarding referral to secondary providers, imaging studies obtained, and participation in physical therapy or hand therapy. Participants were questioned regarding time to return to climbing, degree of recovery, and development of chronic problems related to each injury. Respondents were able to report on all injuries sustained during the 24-month period prior to completing the survey. Information regarding smoking status at the time of injury was also obtained.

\section{Injury Definitions}

An injury event was defined as any climbing-related incident that resulted in time lost from climbing or resulted in an evaluation by a medical provider. A single injury event could result in more than 1 specific injury in separate anatomic locations or even at the same anatomic location. For example, if a finger dislocation and a finger tendon rupture in the same finger both occurred during a single injury event, this was counted as 2 injury types that happened in a single anatomic location during a single injury event.

A tendon strain was defined as an acute injury to a tendon that was previously asymptomatic. This definition included both injuries to the tendon itself, as well as injuries to the tendon pulley. A muscle strain was defined as an acute injury to a muscle that was previously asymptomatic. Tendinitis was defined as an insidious onset, overload injury to a tendon without a clearly defined injury event. For the purposes of this survey, the term "tendinitis" was used instead of tendinopathy, because tendinitis is still a more familiar term to the lay population. No attempt was made to further classify injuries into the acute-on-chronic category, and no attempt was made to differentiate tendon pulley injuries from tendon strain.

For the purposes of this study, the term "extremity" was used synonymously with the term "limb." Injuries to the upper extremity were defined to encompass injuries to the shoulder, arm, elbow, forearm, wrist, and hand. Injuries to the lower extremity were defined to encompass injuries to the thigh, knee, leg, ankle, and foot. The anatomic region "upper arm" was defined as the area between the shoulder and the elbow, and the anatomic region "lower leg" was defined as the area between the knee and the ankle.

\section{Statistical Analysis}

Descriptive statistics were calculated for demographic and injury-related variables. Specifically, frequency and percentage were calculated for qualitative variables, while mean and standard deviation (SD) were calculated for quantitative variables. Injury cases were further stratified by location and type of injury. Descriptive statistics were also obtained for medical coverage and evaluation related to injury. The associations of demographic and injury-related variables to time to return to climbing after injury were examined by the Pearson correlation coefficient, an independent $t$ test, and a 1-way analysis of variance (ANOVA) with the Bonferroni correction for pairwise comparisons in case of a significant ANOVA. Chronic effects after injury, including whether or not the climber developed chronic pain/ problems, whether or not the climber returned to a previous level of performance, and whether or not the climber fully recovered from injury, were described using frequency and percentage. Lastly, the association of climbing type to location and type of injury were analyzed by Pearson's $\chi^{2}$ test.

\section{Results}

Survey data were collected from 553 male climbers and 155 female climbers. The demographic information of the respondents is presented in Table 1. The age of male and female climbers was $28.2 \pm 8.1$ and $30.2 \pm 8.6$ years, respectively. More than half of the respondents reported climbing mostly route grades of 5.10 to 5.11. The respondents were mostly regular climbers, with $77.7 \%$ (550 out of 708 climbers) participating in climbing at least 5 hours per week. Injuries tended to occur mostly 
Table 1. Participant demographics

\begin{tabular}{|c|c|c|c|c|}
\hline Variable $^{a}$ & & Male $(n=553)$ & Female $(n=155)$ & Total $(n=708)$ \\
\hline Age, mean (SD) & & $28.2(8.1)$ & $30.2(8.6)$ & $28.6(8.2)$ \\
\hline Average no. of injury events in prior 2 years & & $2.0(1.3)$ & $1.8(1.0)$ & $2.0(1.3)$ \\
\hline \multirow[t]{4}{*}{ Average weekly climbing hours at time of injury } & $0-1$ & $5(0.9)$ & $0(0.0)$ & $5(0.7)$ \\
\hline & $2-4$ & $106(19.2)$ & $46(29.7)$ & $152(21.5)$ \\
\hline & $5-7$ & $240(43.5)$ & $65(41.9)$ & $305(43.1)$ \\
\hline & 8 or more & $201(36.4)$ & $44(28.4)$ & $245(34.7)$ \\
\hline \multirow[t]{5}{*}{ Average climbing grade at time of injury } & 5.7 or below & $3(0.6)$ & $2(1.3)$ & $5(0.7)$ \\
\hline & $5.8-5.9$ & $51(9.3)$ & $33(21.3)$ & $84(11.9)$ \\
\hline & $5.10-5.11$ & $307(55.8)$ & $91(58.7)$ & $398(56.4)$ \\
\hline & 5.12 or above & $186(33.8)$ & $28(18.1)$ & $214(30.4)$ \\
\hline & Unknown & $3(0.5)$ & $1(0.6)$ & $4(0.6)$ \\
\hline \multirow[t]{3}{*}{ Smoking status } & Never smoked & 407 (73.9) & $130(83.9)$ & $537(76.1)$ \\
\hline & Current smoker & $38(6.9)$ & $3(1.9)$ & $41(5.8)$ \\
\hline & Former smoker & $106(19.2)$ & $22(14.2)$ & $128(18.1)$ \\
\hline \multirow[t]{3}{*}{ Helmet use } & Yes & $61(11.1)$ & $20(13.0)$ & $81(11.5)$ \\
\hline & No & $481(87.5)$ & $131(85.1)$ & $612(86.9)$ \\
\hline & Unknown & $8(1.4)$ & $3(1.9)$ & $11(1.6)$ \\
\hline
\end{tabular}

${ }^{a}$ Values are frequency $(\%)$

on harder climbing routes, with $86.8 \%$ of injuries occurring on routes graded 5.10 or above. The percentage of respondents that indicated that they did not use a helmet when climbing was $86.4 \%$ (612 out of 708 climbers). The percentage of respondents who reported that they did not smoke tobacco at the time of injury was $93.9 \%$ (665 out of 708 climbers). The 708 climbers who responded to the survey reported a total of 1397 injury events that had occurred in the 24 months prior to taking the survey. However, 420 of the reported injury events included incomplete data that were not suitable for analysis. Therefore, the final analysis included the remaining 975 injury events for which complete or nearly complete data were available. These 975 injury events resulted in a total of 1349 specific injuries for which analysis was performed. This survey did not include exposure information, and therefore injury incidence injury was not calculated.

\section{Injuries by Anatomic Location}

The distribution of injuries by anatomic location is reported in Table 2. Some single injury events caused injuries to multiple body regions. As noted in Table 2, of the 1251 reported injuries for which a specific anatomic location was indicated, $71.4 \% \quad(n=893)$ affected the upper extremities, $21.3 \%(n=267)$ affected the lower extremities, and $7.3 \%(n=91)$ affected other regions including the head, spine, and torso. Of the 893 upper extremity injuries recorded, 39.4\% $(n=352)$ affected the fingers, $17.7 \%(n=158)$ affected the shoulders, and
$15.6 \%(n=139)$ affected the elbows. Of the 267 injuries that occurred in the lower extremities, the ankle was the most commonly affected anatomic location (46.8\%, $n=125)$, followed by the knee $(24.0 \%, n=64)$, and foot $(17.6 \%, n=47)$. There were 91 injuries that occurred in other regions. Of the 91 nonlimb injuries, spine $(29.7 \%, \mathrm{n}=27)$ and head $(22.0 \%, \mathrm{n}=20)$ were the most common. However, only $2.2 \%$ of all reported injuries affected the spine.

\section{Types of Injuries}

Injuries by type are summarized in Table 3. Of the 1349 total specific injuries, acute tendon strain was the most common $(31.9 \%, \mathrm{n}=430)$, followed by acute muscle strain $(13.9 \%, \mathrm{n}=188)$, joint sprain $(11.6 \%, \mathrm{n}=156)$, and tendinitis $(11.4 \%, \mathrm{n}=154)$. There were 68 fractures $(5.0 \%), 21$ of which affected the ankle and 17 of which affected the foot. There were 41 joint dislocations $(3.0 \%), 22$ of which occurred in the shoulder. Finger tendon strain injuries were the most common injury type in the upper limb and accounted for $27.8 \%$ (248) of the 893 upper extremity injury events, and $25.4 \%$ of all injury events. Elbow tendonitis $(9.7 \%$, $\mathrm{n}=87)$ and shoulder muscle strains $(7.3 \%, \mathrm{n}=65)$ accounted for the other most common types of injuries affecting the upper limb. Ankle sprains were common, accounting for $59.2 \% \quad(n=74)$ of all ankle injuries $(n=125)$. The most common knee injury reported was tendon strain, followed closely by muscle strain and joint sprain. The least common injury type was concussion 
Table 2. Injuries by anatomic location

\begin{tabular}{|c|c|c|}
\hline Location & & Frequency (\%) \\
\hline \multirow[t]{8}{*}{ Upper extremity } & Fingers & $352(39.4)$ \\
\hline & Hand & $67(7.5)$ \\
\hline & Wrist & $86(9.6)$ \\
\hline & Forearm & $57(6.4)$ \\
\hline & Elbow & $139(15.6)$ \\
\hline & Upper arm & $34(3.8)$ \\
\hline & Shoulder & $158(17.7)$ \\
\hline & $\begin{array}{c}\text { Total upper } \\
\text { extremity }\end{array}$ & $893(71.4)^{a}$ \\
\hline \multirow[t]{6}{*}{ Lower extremity } & Thigh & $18(6.7)$ \\
\hline & Knee & $64(24.0)$ \\
\hline & Lower leg & $13(4.9)$ \\
\hline & Ankle & $125(46.8)$ \\
\hline & Foot & 47 (17.6) \\
\hline & $\begin{array}{c}\text { Total lower } \\
\text { extremity }\end{array}$ & $267(21.3)^{a}$ \\
\hline \multirow[t]{8}{*}{ Other regions (nonlimb) } & Head & $20(22.0)$ \\
\hline & Chest & $5(5.5)$ \\
\hline & Abdomen & $4(4.4)$ \\
\hline & Spine & $27(29.7)$ \\
\hline & Pelvis & $14(15.4)$ \\
\hline & Internal organs & $1(1.1)$ \\
\hline & Other & $20(22.0)$ \\
\hline & Total other regions & $91(7.3)^{a}$ \\
\hline Total & & 1251 \\
\hline
\end{tabular}

${ }^{a}$ Relative to a total number of injuries by body region $(\mathrm{n}=1251)$.

$(1.0 \%, \mathrm{n}=14)$. Because of the small number of concussions and the high percentage of climbers who did not wear helmets, no analysis was performed with regard to the effect of helmet use on concussion rates.

\section{Medical Evaluation by Injured Climbers}

The percentage of injured climbers who sought medical evaluation for a climbing-related injury was $36 \%$ $(n=351)$ (Table 4). Of those who sought medical care, the initial medical evaluation was most often done by primary care providers $(27.9 \%, \mathrm{n}=98)$, followed by emergency physicians $(19.9 \%, \mathrm{n}=70)$, and orthopedic surgeons $(15.7 \%, \mathrm{n}=55)$. The percentage of climbers who had medical insurance and sought medical care for an injury at an ED first was $19.1 \%(\mathrm{n}=62)$, while $30.4 \%$ $(n=7)$ of those who sought medical care but did not have medical insurance sought their initial care in an ED $(P=.189)$. Referral to secondary, subspecialist providers for further diagnosis or treatment was also common and reported by $54.7 \%(192 / 351)$ of the climbers who sought medical care for an injury. The most common providers seen for secondary evaluation
Table 3. Injury type

\begin{tabular}{lr}
\hline Injury type & Frequency $(\%)$ \\
\hline Tendon strain & $430(31.9)$ \\
Muscle strain & $188(13.9)$ \\
Joint sprain & $156(11.6)$ \\
Tendonitis & $154(11.4)$ \\
Bone fracture & $68(5.0)$ \\
Tendon rupture & $67(5.0)$ \\
Blunt trauma & $55(4.1)$ \\
Joint dislocation & $41(3.0)$ \\
Laceration & $29(2.1)$ \\
Nerve injury & $25(1.9)$ \\
Concussion & $14(1.0)$ \\
Other & $20(1.5)$ \\
Unknown & $102(7.6)$ \\
Total & 1349 \\
\hline
\end{tabular}

were rehabilitation therapists (including physical therapists, hand therapists, and athletic trainers) $(58.4 \%, \mathrm{n}=205)$, orthopedic surgeons $(27.4 \%, \mathrm{n}=77)$, and nonsurgical sports medicine physicians (11.7\%, $\mathrm{n}=33$ ).

Imaging studies were frequently used as part of the medical evaluation with a total of 345 imaging studies obtained for the 351 climbers who sought medical care for an injury. In many cases, multiple imaging studies were obtained related to the evaluation of a single individual. Radiographs accounted for $58.8 \%$ of the imaging studies ordered. Magnetic resonance imaging (MRI) (23.8\%), computed tomography (CT) scan (9.3\%), and ultrasound (8.1\%) made up the remainder of the imaging studies obtained.

\section{Factors Associated with Delayed Recovery from Climbing Injury}

A number of factors were associated with delayed recovery from climbing injury (Table 5). Climbers first seen in the ED took about 1.3 months longer to return to climbing than did climbers first seen by nonemergency medical providers $(4.2 \pm 4.2$ months vs $2.9 \pm 4.2$ months, $t=2.303, P=.023)$. This finding was not surprising, as injuries resulting in an ED visit are likely to be more severe than injuries not prompting a visit to an ED. Climbers whose injuries required surgery took significantly more time to return to climbing $(6.2 \pm 5.8$ months vs $2.5 \pm 3.5$ months) compared with those whose injuries did not require surgery $(t=-4.672, P<.001)$. Older age at time of injury was also significantly correlated with longer return to climbing $(r=0.121$, $P<.001)$. Climbers who sustained a fracture took significantly longer to return to climbing compared with 
Table 4. Insurance coverage and types of medical evaluation sought by injured climbers

\begin{tabular}{|c|c|c|c|}
\hline \multirow[b]{2}{*}{ Variable $^{a}$} & & \multicolumn{2}{|c|}{ Insurance coverage } \\
\hline & & Yes & No \\
\hline & & $858(88.7)$ & $109(11.3)$ \\
\hline \multirow[t]{3}{*}{ Sought medical care for injury } & Yes & $325(37.9)$ & $23(21.1)$ \\
\hline & No & $531(61.9)$ & $85(78.0)$ \\
\hline & No response & $2(0.2)$ & $1(0.9)$ \\
\hline \multirow[t]{12}{*}{ Type of care provider seen first } & Personal or family physician & $92(28.3)$ & $5(21.8)$ \\
\hline & $\mathrm{ED}$ & $62(19.1)$ & $7(30.4)$ \\
\hline & Orthopedic surgeon & $54(16.6)$ & $1(4.4)$ \\
\hline & Sports medicine & $38(11.7)$ & $3(13.0)$ \\
\hline & Physical therapist & $23(7.1)$ & $3(13.0)$ \\
\hline & Urgent care & $24(7.4)$ & $1(4.4)$ \\
\hline & Chiropractor & $11(3.4)$ & $2(8.7)$ \\
\hline & Other & $9(2.8)$ & $1(4.3)$ \\
\hline & Physical medicine and rehabilitation & $5(1.5)$ & $0(0.0)$ \\
\hline & Acupuncture & $4(1.2)$ & $0(0.0)$ \\
\hline & Occupational therapist & $3(0.9)$ & $0(0.0)$ \\
\hline & Total & 325 & 23 \\
\hline \multirow[t]{8}{*}{ Referred to another provider } & Orthopedic surgeon & $73(40.1)$ & $3(42.8)$ \\
\hline & Sports medicine & $33(18.1)$ & $0(0.0)$ \\
\hline & Physical medicine and rehabilitation & $24(13.2)$ & $2(28.6)$ \\
\hline & Other & $17(9.3)$ & $2(28.6)$ \\
\hline & Personal or family physician & $12(6.6)$ & $0(0.0)$ \\
\hline & Acupuncture & $12(6.6)$ & $0(0.0)$ \\
\hline & Chiropractor & $11(6.1)$ & $0(0.0)$ \\
\hline & Total & 182 & 7 \\
\hline \multirow[t]{4}{*}{ Referred to therapy } & Physical therapist & $181(94.8)$ & $10(83.4)$ \\
\hline & Hand therapist & $9(4.7)$ & $1(8.3)$ \\
\hline & Athletic trainer & $1(0.5)$ & $1(8.3)$ \\
\hline & Total & 191 & 12 \\
\hline \multirow[t]{5}{*}{ Imaging studies obtained } & X-rays & $190(59.2)$ & $11(55.0)$ \\
\hline & CT scan & $28(8.7)$ & $3(15.0)$ \\
\hline & MRI & $78(24.3)$ & $4(20.0)$ \\
\hline & Ultrasound & $25(7.8)$ & $2(10.0)$ \\
\hline & Total & 321 & 20 \\
\hline
\end{tabular}

CT, computed tomography; MRI, magnetic resonance imaging.

${ }^{a}$ Values are frequency $(\%)$.

climbers who developed tendonitis $(4.4 \pm 4.4$ months vs $1.7 \pm 2.6$ months, $t=4.642, P<.001)$. In addition, there was a trend for injuries that involved the lower extremity to prolong return to climbing compared with injuries involving the upper extremity, although this did not reach statistical significance $(2.1 \pm 3.2$ vs $1.7 \pm 2.8$ months, $t=-1.769, \quad P=.078)$. Meanwhile, there was no significant difference in recovery time based on sex, side of injury, or those covered by health insurance $(P>.05)$.

There were significant differences in recovery time by smoking status $(F=3.923, P=.020)$. The pairwise comparisons with the Bonferroni correction revealed that the time it took to return to climbing was significantly longer in climbers who were current smokers $(2.7 \pm 5.3$ months) than in those who never smoked $(1.7 \pm 2.7$ months, $P=.016)$ or those who were former smokers $(1.7 \pm 2.2$ months, $P=.048)$.

\section{Chronic Effects After Injury}

The percentage of respondents that indicated that their injuries resulted in some degree of chronic pain or functional limitation was $44.9 \%(n=438)$. The percentage of respondents that felt they had not fully recovered from their injury at the time that they returned to climbing was $51.1 \% \quad(\mathrm{n}=498)$, and $28.0 \% \quad(\mathrm{n}=273)$ 
Table 5. Factors associated with delayed recovery from climbing injury

\begin{tabular}{|c|c|c|c|c|}
\hline & & \multicolumn{3}{|c|}{ Time (months) to recover } \\
\hline & & $n$ & Mean $(S D)$ or $r^{a}$ & $P$ \\
\hline Age & & 974 & $r=0.121$ & $<.001$ \\
\hline \multirow[t]{2}{*}{ Sex } & Male & 731 & $1.8(3.0)$ & .522 \\
\hline & Female & 204 & $1.7(2.3)$ & \\
\hline \multirow[t]{3}{*}{ Smoking status } & Never smoked & 697 & $1.7(2.7)$ & .020 \\
\hline & Current smoker & 61 & $2.7(5.3)$ & \\
\hline & Former smoker & 176 & $1.7(2.2)$ & \\
\hline \multirow[t]{2}{*}{ Injury location } & Upper extremity & 674 & $1.7(2.8)$ & .078 \\
\hline & Lower extremity & 225 & $2.1(3.2)$ & \\
\hline \multirow[t]{2}{*}{ Injury type } & Fracture & 63 & $4.4(4.4)$ & $<.001$ \\
\hline & Tendinitis & 147 & $1.7(2.6)$ & \\
\hline \multirow[t]{2}{*}{ Injury side } & Dominant & 350 & $1.9(2.9)$ & 0.403 \\
\hline & Nondominant & 379 & $1.7(2.5)$ & \\
\hline \multirow[t]{2}{*}{ Insurance coverage } & Yes & 827 & $1.7(2.9)$ & 0.765 \\
\hline & No & 101 & $1.7(2.4)$ & \\
\hline \multirow[t]{2}{*}{ First seen healthcare provider } & ED & 66 & $4.2(4.2)$ & 0.023 \\
\hline & Non-ED & 262 & $2.9(4.2)$ & \\
\hline \multirow[t]{2}{*}{ Surgery required } & Yes & 57 & $6.2(5.8)$ & $<0.001$ \\
\hline & No & 267 & $2.5(3.5)$ & \\
\hline
\end{tabular}

ED, emergency department.

${ }^{a} r=$ correlation coefficient.

indicated they were unable to return to their prior level of performance.

\section{Location and Type of Injury by Type of Climbing Activity}

Tables 6 and 7 summarize injury location and type of injury by type of climbing activity. Injury patterns differed by the type of climbing activity. Among the injury events for which the type of climbing activity was reported $(n=974)$, more than half of the climbers $(57.0 \%)$ were climbing in an indoor climbing gym at the time of injury, followed by $18.8 \%$ of climbers injured while doing outdoor bouldering, $14.8 \%$ of climbers injured while engaging in outdoor sport climbing, and 9.4\% of climbers injured while doing traditional climbing. No attempt was made to collect data on the percent of time that the climbers spent in each type of climbing activity, and therefore injury incidence rates by type of climbing activity could not be calculated. Climbers sustained a significantly higher percentage of upper extremity injuries during indoor climbing compared with the 3 outdoor types of climbing activities $(62.9 \%, P<$ .001). On the other hand, injuries of the lower extremities, head, and spine occurred more frequently during outdoor bouldering, outdoor sport, and traditional climbing $(P<.001)$. Specifically, significantly higher percentages of climbers had injuries of the lower extremities and other regions during traditional climbing (22.5\% and $23.1 \%, P<.001$, respectively) compared with the percentage of all injuries that occurred during traditional climbing $(9.4 \%)$. Tendon strain occurred significantly more often during indoor climbing $(65.7 \%, P<.001)$. The risk of fracture was significantly higher during outdoor bouldering $(29.4 \%, P<.001)$, and climbers sustained a significantly higher percentage of concussions during outdoor sport $(42.9 \%)$ and traditional climbing $(35.7 \%)$ than during indoor climbing or outdoor bouldering $(P<.001)$.

\section{Discussion}

As climbing increases in popularity, it becomes imperative for medical providers to better understand climbing-related injuries. This includes recognizing injury patterns and injury mechanisms, identifying risk factors, and initiating appropriate treatment. The existing data regarding the distribution and type of climbing injury is relatively robust. However, the literature regarding patterns of healthcare referral, injuries by type of climbing activity, and factors associated with return to climbing are lacking. The primary aims of this study were to expand upon the existing body of knowledge and describe the patterns of healthcare providers seen for 
Table 6. Injury location by climbing type

\begin{tabular}{|c|c|c|c|c|c|c|}
\hline \multirow[b]{2}{*}{ Location } & & \multicolumn{4}{|c|}{ Climbing type (total $N=974)$} & \multirow[b]{2}{*}{$P^{b}$} \\
\hline & & $\begin{array}{c}\text { Indoor climbing } \\
\text { gym }(n=555,57.0 \%)^{a}\end{array}$ & $\begin{array}{c}\text { Outdoor bouldering } \\
(n=183,18.8 \%)\end{array}$ & $\begin{array}{c}\text { Outdoor sport } \\
(n=144,14.8 \%)\end{array}$ & $\begin{array}{c}\text { Traditional } \\
(n=92,9.4 \%)\end{array}$ & \\
\hline \multirow[t]{8}{*}{ Upper extremity } & Fingers & $245(69.8)$ & $53(15.1)$ & $38(10.8)$ & $15(4.3)$ & $<.001$ \\
\hline & Hand & $40(59.7)$ & $14(20.9)$ & $7(10.4)$ & $6(9.0)$ & .754 \\
\hline & Wrist & $50(58.1)$ & $21(24.4)$ & $9(10.5)$ & $6(7.0)$ & .332 \\
\hline & Forearm & $38(66.7)$ & $11(19.3)$ & $7(12.3)$ & $1(1.8)$ & .168 \\
\hline & Elbow & $84(60.4)$ & $27(19.4)$ & $22(15.8)$ & $6(4.3)$ & .171 \\
\hline & Upper arm & $19(55.9)$ & $9(26.5)$ & $5(14.7)$ & $1(2.9)$ & .442 \\
\hline & Shoulder & $85(53.8)$ & $26(16.5)$ & $26(16.5)$ & $21(13.2)$ & .242 \\
\hline & Total & $561(62.9)$ & $161(18.0)$ & $114(12.8)$ & $56(6.3)$ & $<.001$ \\
\hline \multirow[t]{6}{*}{ Lower extremity } & Thigh & $8(44.4)$ & $4(22.2)$ & $1(5.6)$ & $5(27.8)$ & .042 \\
\hline & Knee & $27(42.2)$ & $10(15.6)$ & 14 (21.9) & $13(20.3)$ & .003 \\
\hline & Lower leg & $4(30.8)$ & $3(23.1)$ & $2(15.4)$ & $4(30.8)$ & .045 \\
\hline & Ankle & $48(38.4)$ & $31(24.8)$ & $20(16.0)$ & $26(20.8)$ & $<.001$ \\
\hline & Foot & 15 (31.9) & $9(19.1)$ & $11(23.4)$ & $12(25.5)$ & $<.001$ \\
\hline & Total & $102(38.2)$ & $57(21.3)$ & $48(18.0)$ & $60(22.5)$ & $<.001$ \\
\hline \multirow[t]{8}{*}{ Other region } & Head & $2(10.0)$ & $3(15.0)$ & $7(35.0)$ & $8(40.0)$ & $<.001$ \\
\hline & Chest & $0(0.0)$ & $1(20.0)$ & $1(20.0)$ & $3(60.0)$ & .001 \\
\hline & Abdomen & $1(25.0)$ & $0(0.0)$ & $3(75.0)$ & $0(0.0)$ & .008 \\
\hline & Spine & $10(37.0)$ & $6(22.2)$ & $6(22.2)$ & $5(18.5)$ & .134 \\
\hline & Pelvis & $2(14.3)$ & $6(42.9)$ & $4(28.6)$ & $2(14.3)$ & .011 \\
\hline & Internal organs & $0(0.0)$ & $0(0.0)$ & $1(100.0)$ & $0(0.0)$ & .123 \\
\hline & Other & $9(45.0)$ & $6(30.0)$ & $2(10.0)$ & $3(15.0)$ & .413 \\
\hline & Total & $24(26.4)$ & $22(24.2)$ & $24(26.4)$ & $21(23.1)$ & $<.001$ \\
\hline
\end{tabular}

${ }^{a}$ Values are frequency $(\%)$.

${ }^{b} P$ obtained from $\chi^{2}$ test.

climbing injuries, report on climbing injuries by type of climbing activity, and characterize factors associated with delayed of impaired return to climbing.

Most climbing injuries are not necessarily treated differently compared with other sports injuries, although knowledge of climbing types and climbing specific injuries will assist in diagnosis and treatment, and will help guide return to climbing activities. Treatments include, but are not limited to, the application of standard care principles such as relative rest and activity modification. Given the prevalence of strain and overuse type injuries, physical therapy and hand therapy often play an important role in injury treatment. Biomechanical evaluation and treatment of muscle imbalances are key elements of the therapeutic approach. Eccentric exercises have gained favor for the treatment of tendon injuries, especially tendinopathy. Recent literature reviews have suggested that eccentric exercises are beneficial for tendon overload injuries. ${ }^{17,18}$ The mechanism of climbing injury is always important to elicit. Acute injuries are often treated differently from insidious onset, overuse injuries. Tendon ruptures and finger pulley injuries often require a period of immobilization or surgery. Due to falls from height, some injuries may involve high-energy trauma. In this setting, it is important to consider and rule out fractures.

This cohort of survey respondents represented a moderately regular and experienced group of climbers, with nearly $80 \%$ participating in climbing 5 or more hours per week and climbing grades of 5.10 to 5.11 . Nearly $90 \%$ of respondents had health insurance, making cost less of a barrier for access to medical care.

With regard to the anatomic location of injuries, the climbers in this study reported a similar anatomic distribution of injuries compared with what has been reported in the existing literature. Our cohort of respondents reported that $71.4 \%$ of all injuries affected the upper extremity, which is near the top of the range of the frequency of upper limb injuries reported in other studies of 42.6 to $81 \% .^{5,6,8,19,20}$ The frequency of finger injuries in this study was also within the range previously reported in the literature, ${ }^{5,6,8,19,20}$ with finger tendon strains and tendonitis accounting for the majority of finger injuries. This study found that lower limb injury occurred less commonly than upper limb injuries and represented a more heterogeneous group of injury types. 
Table 7. Injury type by climbing type

\begin{tabular}{|c|c|c|c|c|c|}
\hline \multirow[b]{2}{*}{ Injury type } & \multicolumn{4}{|c|}{ Climbing type (total $n=974$ ) } & \multirow[b]{2}{*}{$P^{b}$} \\
\hline & $\begin{array}{c}\text { Indoor climbing } \\
\text { gym }(n=555,57.0 \%)^{a}\end{array}$ & $\begin{array}{c}\text { Outdoor bouldering } \\
(n=183,18.8 \%)\end{array}$ & $\begin{array}{c}\text { Outdoor sport } \\
(n=144,14.8 \%)\end{array}$ & $\begin{array}{c}\text { Traditional } \\
(n=92,9.4 \%)\end{array}$ & \\
\hline Muscle strain & $103(54.8)$ & $42(22.3)$ & $29(15.4)$ & $14(7.4)$ & .422 \\
\hline Tendon strain & $282(65.7)$ & $75(17.5)$ & $49(11.4)$ & $23(5.4)$ & $<.001$ \\
\hline Tendon rupture & $42(62.7)$ & 7 (10.4) & $14(20.9)$ & $4(6.0)$ & .121 \\
\hline Tendonitis & $97(63.0)$ & $24(15.6)$ & $23(14.9)$ & $10(6.5)$ & .278 \\
\hline Joint sprain & $74(47.4)$ & $40(25.6)$ & $23(14.7)$ & $19(12.2)$ & .028 \\
\hline Joint dislocation & $17(41.5)$ & $9(22.0)$ & $7(17.1)$ & $8(19.5)$ & .079 \\
\hline Bone fracture & $22(32.4)$ & $20(29.4)$ & $8(11.8)$ & $18(26.5)$ & $<.001$ \\
\hline Blunt trauma & $12(21.8)$ & $14(25.5)$ & $11(20.0)$ & $18(32.7)$ & $<.001$ \\
\hline Laceration & $6(20.7)$ & $7(24.1)$ & $9(31.0)$ & $7(24.1)$ & $<.001$ \\
\hline Concussion & $1(7.1)$ & $2(14.3)$ & $6(42.9)$ & $5(35.7)$ & $<.001$ \\
\hline Nerve injury & $11(44.0)$ & $2(8.0)$ & $7(28.0)$ & $5(20.0)$ & .038 \\
\hline Other & $9(45.0)$ & $6(30.0)$ & $2(10.0)$ & $3(15.0)$ & .413 \\
\hline Unknown & $53(52.0)$ & $23(22.5)$ & $16(15.7)$ & $10(9.8)$ & .696 \\
\hline
\end{tabular}

${ }^{a}$ Values are frequency $(\%)$.

${ }^{b} P$ obtained from $\chi^{2}$ test.

This is also consistent with data previously reported in the literature. ${ }^{6,8,13,14,19,20}$ Many injuries sustained by climbers do not require specific medical treatment. However, $35.9 \%$ of injuries in our study caused the climber to seek medical care. This value is similar to that noted by Jones et al who reported that $38 \%$ of injured climbers had sought medical treatment or advice. ${ }^{7}$

As noted above, the most common provider seen by climbers for initial evaluation was a primary care provider. Referral for consultation with other medical providers was common and reported by $80.1 \%$ of all injured climbers who sought medical care. This indicates that the provider who first saw the injured climber was often not able to provide definitive care. Orthopedic surgeons, nonoperative sports medicine providers, and physical therapists were frequently seen in consultation. Given that a surprisingly high percentage $(51.1 \%)$ of climbers reported incomplete recovery at the time they returned to climbing and/or developed chronic problems (44.9\%) related to a climbing injury, healthcare providers who see these injuries should consider early subspecialty evaluation and promote complete rehabilitation of injuries. Similar findings were published in a recent survey in which $41 \%$ of climbers reported that their injuries caused some pain or functional limitation at least 11 days per month. ${ }^{21}$ Twenty-eight percent of respondents in our cohort reported that they had not returned to their previous level of climbing following an injury, raising further concern about incomplete medical treatments.

This study suggests that imaging studies are an integral part of the medical evaluation of climbing injuries. Radiographs were the most commonly used imaging modality, followed by MRI. Although not as frequently reported by this cohort, ultrasound is proving to be an excellent tool for evaluation of the injured climber, particular for tendon pathology. A recent review article on the diagnosis of climbing-related finger injuries suggested that dynamic ultrasound was highly accurate for the diagnosis of finger pulley injuries. ${ }^{22}$ Another review article on the imaging of climbing injuries also emphasized that ultrasound had distinct advantages for imaging finger injuries, including high spatial resolution and dynamic capabilities. $^{23}$ These features make ultrasound an important tool for imaging tendons, ligaments, nerves, and other soft tissues. As only $8 \%$ of imaging studies obtained in this cohort of injured climbers were ultrasound studies, it is possible that the treating providers underutilized this imaging modality.

This study demonstrated statistically significant differences in the injury patterns associated with the different types of climbing activity with regard to both anatomic location and types of injury. A higher percentage of upper limb injuries and a higher percentage of tendon injuries occurred during indoor climbing compared with outdoor climbing activities. There are several possible explanations for these differences. It may be that climbers are typically in a "training mentality" while climbing indoors and push themselves harder and longer, thus increasing the chance for flexor tendon overload injury in the fingers. It could also be that climbers feel safer while climbing indoors, and therefore exert more extreme effort compared with climbing outdoors when they are in settings that might be considered less protected or less safe, resulting in more cautious 
climbing. This study also found that climbers are more likely to sustain a limb fracture when participating in outdoor bouldering as compared with other climbing types. This is probably secondary to a higher risk of falling unprotected from heights during outdoor bouldering. As one would expect, there was a higher frequency of concussion associated with outdoor sport and traditional climbing where there is a higher risk of rocks and other objects falling from above, in addition to having a higher risk of falls.

A number of factors were associated with delayed recovery from climbing injury. Injuries that were initially seen in an ED resulted in nearly $50 \%$ greater time away from climbing compared with injuries that were not initially seen in an ED. Presumably, this is because an injury that causes a climber to seek emergent care is typically more severe than injuries that do not cause a climber to seek emergent care. We observed that a proportion of climbers without medical insurance who sought medical care for injury visited an ED greater than the proportion of those with medical insurance in this study (19.1 vs 30.4\%). We conducted a follow-up analysis and found that these 2 proportions were not significantly different $(z=-1.313, P=.189)$. Therefore, the influence of medical insurance status on recovery from climbing injury in relation to an ED visit was minimal in our study. As expected, fractures and all injuries requiring surgery resulted in a significantly longer time to return to climbing. Age was also shown to be a factor, with older age associated with longer recovery time. Interestingly, there was no difference in time to return to climbing between those with and without medical insurance. While the reasons for this finding are not evident from our data, one might conjecture that a climber's insurance status does not affect either the nature of their injuries or their utilization of healthcare resources. Alternatively, our data may have been underpowered to detect a difference in time lost from climbing based on insurance status, especially given that a relatively low percentage of respondents reported having no medical insurance.

It is favorable that only $5.8 \%$ of the survey respondents were smokers. However, even with this relatively small percentage, the analysis showed that smoking at the time of injury was clearly associated with delayed recovery from climbing injury. Those smoking regularly at the time of injury reported an average return to climbing of 2.7 months. This finding is in contrast to the time of 1.7 months reported by nonsmokers $(P=.02)$. Other studies have also suggested that smoking is associated with poor bone and soft tissue healing. ${ }^{24,25}$ Some existing research also suggests that smoking may be a risk factor for musculoskeletal injury or fracture. ${ }^{26}$ Since our study was an observational study, we were unable to make a causal inference of smoking on recovery of injuries. Yet, research has shown that smoking is associated with an increased risk of postoperative complications of wound and fracture healing, ${ }^{27-29}$ whereas smoking cessation can reduce the risk. $^{30,31}$ Healthcare providers should counsel climbers on the risks of smoking, both with regard to their musculoskeletal system in addition to their general health.

\section{Limitations}

The retrospective, cross sectional design of this study has several inherent limitations. Although associations may be determined, direct cause and effect cannot be established. Exposure data (eg, injury rate per time) and mechanisms of injury were not obtained. Some degree of recall bias is likely given the study design. The study relied on participants to recall injuries sustained in the 24 months prior to when they completed the survey. Participants may have been more likely to report severe, significant, or memorable injuries. Climbers may not have remembered or reported all of the injuries sustained during this time period, and may not have recalled some of the medical details surrounding their injuries. Actual medical records were not reviewed. The study was administered as an online survey that may have biased the group of survey responders toward climbers who frequent climbing websites. The climbers who responded and completed the survey may not represent an accurate cross section of the general climbing population. Climbers whose injuries resulted in severe disability and climbers who sustained very minor injuries may also have been less likely to participate. Another important and related limitation of this report is that it does not include a standardized injury severity grading scale, such as the International Climbing and Mountaineering Federation (UIAA) Medical Commission Injury Classification, ${ }^{32}$ which limits the ability to compare the results of this investigation with other reports on climbing injuries. We used time lost from climbing as a proxy measure for severity of injury. We recognized some challenges that made it difficult to incorporate the UIAA classification for climbing injuries into this study. First, the initial study design of our project did not include a standard injury grading score; therefore, the data do not lend themselves to retroactively applying one. Second, the UIAA classification does not allow for certain elements of granularity that were obtained with our survey, such as the specific nature of injuries (ie, tendon overuse injury, acute tendon injury, fracture, concussion, etc.). Third, the majority of the UIAA classification scheme, as 
published, is not pertinent to our data set, such as the fatality risk classification, the illness section, and the time-related injury risk (another limitation of our study design). Most importantly, the UIAA Severity Classification, which is graded on a 1 to 6 scale, cannot be applied to our data set as the variables are entirely distinct. We understand, however, that it will be important to include standardized injury grading classification in our future sports epidemiology research. Finally, while nearly $90 \%$ of the respondents had medical insurance, those that did not have medical insurance and those that were underinsured could have altered how and when they accessed the healthcare system because of financial concerns.

\section{Conclusions}

Rock climbing is a growing indoor and outdoor sport with inherent risks. Climbing injuries represent a heterogeneous group of musculoskeletal injuries. Overuse and strain type injuries are more common than fall-related traumatic injuries, especially in the upper extremity. The upper extremity is the most commonly injured body region, with the fingers being the most single most common anatomic location for injury. Acute and insidious overload injuries of the finger flexor tendons are especially common. While tendon injuries are also common in the lower extremities, ankle sprains and fractures of the foot and ankle account for a fairly high percentage of all lower extremity climbing injuries. Climbers sought initial medical care from a variety of types of providers and referral to subspecialists was common. Imaging studies were frequently used in the evaluation of climbing injuries, although diagnostic ultrasound may have been underutilized, particularly for tendon injuries. Injury patterns differed depending on the type of climbing activity. Factors associated with delayed recovery from climbing injury included injuries first seen in an ED, fractures, injuries requiring surgery, increasing age, and smoking. About half of the injured climbers reported that their symptoms were not fully resolved at the time that they returned to climbing, and a similar percentage reported the development of chronic pain and problems after injury, raising concern about incomplete treatment of climbing injuries.

Author Contributions: Study concept and design (AMH, JWM, EM); obtaining funding (not applicable); acquisition of the data $(\mathrm{AMH}$, JWM); analysis of the data (SEW, AMH, JWM, MT); drafting of the manuscript (SEW, AMH, JWM, MT); critical revision of the manuscript (SEW, AMH, JWM, MT); approval of final manuscript (SEW, AMH, JWM, MT).

Financial/Material Support: None.

Disclosures: None.

\section{References}

1. The Outdoor Foundation. Outdoor Participation Report 2013. Available at: http://www.outdoorfoundation.org/pdf/ ResearchParticipation2013.pdf. Accessed January 23, 2017.

2. Division of Utah State Parks and Recreation Planning Section. Utah State Comprehensive Outdoor Recreation Plan 2014. Available at: http://static.stateparks.utah.gov/docs/ SCORP2014.pdf. Accessed January 23, 2017.

3. Sheel AW. Physiology of sport rock climbing. Br J Sports Med. 2004;38:355-359.

4. Schussman L, Lutz L, Shaw R, Bohnn C. The epidemiology of mountaineering and rock climbing accidents. J Wilderness Med. 1990;1:235-248.

5. Backe S, Ericson L, Janson S, Timpka T. Rock climbing injury rates and associated risk factors in a general climbing population. Scand J Med Sci Sports. 2009; 19:850-856.

6. Gerdes EM, Hafner JW, Aldag JC. Injury patterns and safety practices of rock climbers. J Trauma. 2006;61: $1517-1525$.

7. Jones G, Asghar A, Llewellyn DJ. The epidemiology of rock-climbing injuries. $\mathrm{Br} J$ Sports Med. 2008;42: 773-778.

8. Neuhof A, Hennig FF, Schoffl I, Schoffl V. Injury risk evaluation in sport climbing. Int J Sports Med. 2011;32: 794-800.

9. Schoffl V, Morrison A, Schwarz U, Schoffl I, Kupper T. Evaluation of injury and fatality risk in rock and ice climbing. Sports Med. 2010;40:657-679.

10. Limb D. Injuries on British climbing walls. Br J Sports Med. 1995;29:168-170.

11. Logan AJ, Makwana N, Mason G, Dias J. Acute hand and wrist injuries in experienced rock climbers. $\mathrm{Br} J$ Sports Med. 2004;38:545-548.

12. Addiss DG, Baker SP. Mountaineering and rock-climbing injuries in US national parks. Ann Emerg Med. 1989; 18:975-979.

13. Bowie WS, Hunt TK, Allen HA Jr. Rock-climbing injuries in Yosemite National Park. West J Med. 1988; 149:172-177.

14. Nelson NG, McKenzie LB. Rock climbing injuries treated in emergency departments in the US, 1990-2007. Am J Prev Med. 2009;37:195-200.

15. Kubiak EN, Klugman JA, Bosco JA. Hand injuries in rock climbers. Bull NYU Hosp Jt Dis. 2006;64:172-177.

16. Schweizer A. Biomechanical properties of the crimp grip position in rock climbers. J Biomech. 2001;34:217-223.

17. Andres BM, Murrell GA. Treatment of tendinopathy: what works, what does not, and what is on the horizon. Clin Orthop Relat Res. 2008;466:1539-1554.

18. Woodley BL, Newsham-West RJ, Baxter GD. Chronic tendinopathy: effectiveness of eccentric exercise. $\mathrm{Br} J$ Sports Med. 2007;41:188-199.

19. Holtzhausen LM, Noakes TD. Elbow, forearm, wrist, and hand injuries among sport rock climbers. Clin J Sport Med. 1996;6:196-203. 
20. Schoffl V, Morrison A, Schoffl I, Kupper T. The epidemiology of injury in mountaineering, rock and ice climbing. Med Sport Sci. 2012;58:17-43.

21. Folkl AK. Characterizing the consequences of chronic climbing-related injury in sport climbers and boulderers. Wilderness Environ Med. 2013;24:153-158.

22. El-Sheikh Y, Wong I, Farrokhyar F, Thoma A. Diagnosis of finger flexor pulley injury in rock climbers: a systematic review. Can J Plast Surg. 2006;14:227-231.

23. Martinoli C, Bianchi S, Cotten A. Imaging of rock climbing injuries. Semin Musculoskelet Radiol. 2005;9:334-345.

24. Hernigou J, Schuind F. Smoking as a predictor of negative outcome in diaphyseal fracture healing. Int Orthop. 2013; 37:883-887.

25. Santiago-Torres J, Flanigan DC, Butler RB, Bishop JY. The effect of smoking on rotator cuff and glenoid labrum surgery: a systematic review. Am J Sports Med. 2015;43:745-751.

26. Altarac M, Gardner JW, Popovich RM, Potter R, Knapik JJ, Jones BH. Cigarette smoking and exercise-related injuries among young men and women. Am J Prev Med. 2000;18(suppl 3):96-102.
27. Scolaro JA, Schenker ML, Yannascoli S, Baldwin K, Mehta S, Ahn J. Cigarette smoking increases complications following fracture: a systematic review. J Bone Joint Surg Am. 2014;96:674-681.

28. Porter SE, Hanley EN Jr. The musculoskeletal effects of smoking. J Am Acad Orthop Surg. 2001;9:9-17.

29. Sloan A, Hussain I, Maqsood M, Eremin O, El-Sheemy M. The effects of smoking on fracture healing. Surgeon. 2010;8:111-116.

30. Sorensen LT. Wound healing and infection in surgery. The clinical impact of smoking and smoking cessation: a systematic review and meta-analysis. Arch Surg. 2012;147: 373-383.

31. Nasell H, Adami J, Samnegard E, Tonnesen H, Ponzer S. Effect of smoking cessation intervention on results of acute fracture surgery: a randomized controlled trial. J Bone Joint Surg Am. 2010;92:1335-1342.

32. Schoffl V, Morrison A, Hefti U, Ullrich S, Kupper T. The UIAA Medical Commission injury classification for mountaineering and climbing sports. Wilderness Environ Med. 2011;22:46-51. 